\title{
Research on the Participation of University-affiliated Think Tanks in Local Economic Development
}

\author{
Zijun Tang ${ }^{1, a}$ \\ ${ }^{1}$ Office of Scientific Research Management Jishou University Jishou Hunan China
}

\begin{abstract}
The basic function of modern university is to train talents, produce and disseminate scientific knowledge, and promote technological progress. As an important birthplace of high technology, universities are the natural matrix of good think tanks. Compared with the government-affiliated think-tanks and the social think tanks, the universityaffiliated think tanks have some unique advantages, such as the concentrated embodiment of the university resources, the role of the third party of non-profit, more advanced and standardized operational model, and the strong scientific research foundation and ability. Therefore, in the current period of important strategic opportunities for local economic and social development, the construction of university-affiliated think tanks should be strengthened, giving full play to the role of university-affiliated think tanks, so as to promote local economic development.
\end{abstract}

\section{Introduction}

With the accelerated evolution of new scientific and technological revolution and industrial transformation, the innovation of science and technologe has become the leading factor of industrial upgrading, high-tech industry has become the main driving force of local economic development. The rapid development of science and technology brings the complexity and specialization to the decision-making of scientific and technological affairs. This situation puts forward realistic requirements and challenges to the local governments. The basic function of modern university is to train talents, produce and disseminate scientific knowledge, promote technological progress, and be the institutional guarantee of free scholarship [1]. It can be said that universities are the embodiment of science and technology, is the natural matrix of think tanks. Compared with other types of think tanks, university-affiliated think tanks have a strong foundation of scientific research in the field of emerging technology, innate disciplinary advantages in support of advanced ideas, methods and means, and abundant intellectual resources in terms of experts and scholars. Therefore, in the face of the diversified, professional needs of science and technology for the current local social and economic development, how to take advantage of the university-affiliated think tanks then deeply participate in local economic development, will become a new mission for universities in the new period.

\section{Advantages of university-affiliated think tanks participating in local economic development}

\subsection{University-affiliated think tanks are the concentrated embodiment of superior resources owned by the universities}

\begin{abstract}
Universities are an important part of China's science and technology innovation system, and the main force of theoretical, basic and frontier research, which have a lot of advantages such as complete discipline system, talent density, strong knowledge reserve, solid foundation of innovation research and so on [2]. Relying on the high quality resources and strong ability of universities, the university-affiliated think tanks has the strong backing of human resources, scientific research foundation, theoretical and policy reserve, ideological innovation and so on. They are the concentrated display of the comprehensive strength or the resources of the universities, as well as the important channel of the transformation and dissemination of intellectual resources from the universities to the government and society, and the spillover effect is very obvious, which can provide strong support for the local economic development.
\end{abstract}

\subsection{University-affiliated think tanks play the role of the third party of non-profit}

At present, there are a large number of government think

\footnotetext{
a Corresponding author: zijuntang@163.com
} 
tanks and social think tanks in China. Government think tanks are closely linked to relevant government departments and are even an important part of the system and chain of government decision-making. Therefore, they have an important impact on government decision-making, but it is also difficult to get rid of issues such as official colors within the system and complex relationships with the government. As far as the social think tanks are concerned, in view of the current situation, it is not enough and there is still a lot of room for them to participate in and influence on government decision-making. Compared with these two think tanks, the university-affiliated think tanks have a relatively independent and moderate position and relationship with the government, representing the objective scientific justice and the general interests of the public. Whether plays as an advisory board or publicity group, the role of the university-affiliated think tanks make them have a stronger credibility. Moreover, the characteristics of independent, nonprofit third part which the university-affiliated think tanks have, may also make them be the preferred ones for government policy makers.

\subsection{University-affiliated think tanks have advanced and standardized operational model}

Constrained by the institutional mechanism, it is difficult for the government think tanks to fully apply advanced ideas and methods to improve its governance structure and operation model. Social think tanks have advantages in management mechanism, governance structure, influence of public opinion, etc., but there may also be problems such as chaotic capital background and loose management. Universities are a relatively complex but flexible system, can accommodate the coexistence and development of different types of institutions, and create a more suitable and powerful policy environment and institutional environment for the growth of new think tanks. With the advantages of resources, standardized management and advanced ideas, the university-affiliated think tanks often take the initiative to seek innovative operation mechanism, governance structure, talent team, technological platform and other innovations, but at the same time also subject to the guidance and constraints of universities. This flexible system which owned by the university-affiliated think tanks, both advanced and normative, can bring new ideas to the development of local economy.

\subsection{University-affiliated think tanks have excellent genes for the consultation of decision-making}

The work of scientific research has always been the core competence of the universities, and is also an important focus of their construction and development. Meanwhile the work of scientific research itself contains a lot of thinktank work. Engaged in the work of scientific research, especially innovative one, needs to fully investigate the current situation of domestic and abroad, master the latest progress in the field, and form a judgment on specific issues through comparison, analysis, induction and thinking progress. This process has a high degree of overlap with the main process of research and consulting by think tanks. Moreover, in practice there are many important suggestions for scientific and technological decisions come from the early preparation works of largescale scientific research activities. On the premise that the mechanism of the two processes is more consistent, universities with the high maturity of the scientific research system play the role of think tanks, which not only takes the advantages of universities, but also reduces the construction cost of think tanks. The advantages are obvious.

\subsection{University-affiliated think tanks have the foundation and ability of scientific research}

Local economic development is an open and complex system work, which needs the vision of cross-integration in multi-disciplinary fields, the research methods and means of combining qualitative and quantitative, and the technological innovation and transformation channels that need to be combined with basic research and applied research. Historically, universities themselves have been the main players in many major scientific projects, with strong capabilities and research base of scientific research. At present, with the traditional advantages of advanced technology research, the university-affiliated think tanks not only have the conditions and foundation to carry out traditional scientific research, but also constantly strengthen the cutting-edge scientific research based on big data technology and intelligent technology, such as data analysis, model reasoning, policy deduction, etc. This large, cutting-edge scientific research is hard to conduct by other types of think tanks. With these advantages, the universityaffiliated think tanks can form three spiral curves: the knowledge transformation curve, the technological innovation curve and the talent rotation curve. These three curves of knowledge, technology and talents are closely coupled and influenced by each other, which is the intrinsic characteristic embodied in the unique natural advantages of the university-affiliated think tanks.

\section{Suggestions on the participation of the university-affiliated think tanks in local economic development}

\subsection{University-affiliated think tanks explore channels and platforms for participating in the development of local economic development}

Firstly, the university-affiliated think tanks should take the initiative to participate in various consultation activities of decision-making organized by local government, actively undertake research projects, and invite the personnel of local government departments or research institutions so as to strengthen the connection between the think tanks and the government. Secondly, the university-affiliated think tanks should monitor the world's major technology trends, follow up the study of major national projects, timely formation of research reports for the reference for the policy-making of government departments. Thirdly, the university-affiliated think tanks, as a third party, should 
participate in the evaluation of local economic projects, conduct independent assessment on local economic development strategies and policies, etc. [3]. Currently, a lot of information websites of local governments release information regularly on scientific and technological needs, which deserves sustained attention.

\subsection{University-affiliated think tanks improve the analysis and research ability on economic development policy}

The university-affiliated think tanks should constantly strengthen their analysis and research capabilities on economic development strategies and policy. Firstly, according to the functional orientation, the universities should scientifically plan the overall construction of think tanks, innovatie organizational forms and governance methods, highlight their own characteristics and advantages. Secondly, the university-affiliated think tanks should strengthen the communication with local government, emphasize the demand, problem and application orientation, so as to enhance the ability of research and evaluation on practical issues, then provide scientific, targeted and professional research results for government decision-making. Thirdly, the universityaffiliated think tanks should strengthen the efficiency of decision-making, not for profit, but to introduce marketoriented operation into the local consulting markets on economic development and to become the "unicorn" of the think-tank industry;

\subsection{University-affiliated think tanks gather related academic research resources and social resources}

For the complex system of local economic development, a single think tank or the combination of multiple think tanks are unable to meet its needs. However, it needs to share resources, joint research to build a system. Firstly, the university-affiliated think tanks should strengthen exchanges and cooperation with other decision-making bodies and scientific research institutes, and jointly set up professional think tanks or joint research groups ; Secondly, the university-affiliated think tanks should participate in relevant collaborative organizations, expert organizations or academic groups, take advantage of the collaborative platforms to expand impact; Thirdly, according to the subject advantage and cross-integration situation, the university should explore the establishment of universityaffiliated think tanks alliance, sharing data, technology, platform, facilities, talent and other resources [4].

\subsection{University-affiliated think tanks develop the intelligent data-based research tools}

At present, the Internet plus, big Data, artificial intelligence and other disruptive technologies have risen. The university-affiliated think tanks can no longer stay in the original mode of work should develop the application of new intelligent research tools, open up new ways of working. Firstly, the university-affiliated think tanks should develop intelligent big data analysis and research tools that meet the actual work needs, and fulfil the collaboration of consulting work with modern tools; Secondly, the university-affiliated think tanks should cooperate deeply with data software companies, etc., and carry out research with the help of advanced tools and abundant resources; Thirdly, the university-affiliated think tanks should strengthen empirical investigation and research, establish new methods, new means and tools based on data and intelligent technology, and put forward policy suggestions and problem solutions based on facts and data basis; Fourthly, with the combination of qualitative and quantitative research methods to become the mainstream, the university-affiliated think tanks should develop integrated platform to realize the automatic and intelligent decision system which combines human, machine and network as early as possible [5].

\subsection{University-affiliated think tanks strengthen the transformation and application of research achievements to local economic development}

The science of information has the concept of "Sleeping Beauty Literature", the field of think tank also has the same problems that a lot of good research achievements are frozen or forgotten, mainly because the channel of transformation is not smooth, or do not meet the needs of the practice, or academic properties are too strong, or the incentive mechanism of transformation and application is missing and so on. Therefore, the university-affiliated think tanks should resolve the issue of the "last mile" of the transformation and application of the research achievements. Firstly, the university-affiliated think tanks should figure out the specific or potential needs of local economic development, regularly produce the latest brief of achievements for the reference of decision-making departments of government. Secondly, the universityaffiliated think tanks should use the opportunities of conference exchanges, as well as local information network of science and technology needs and other platforms, to publicize and promote research achievements and demonstrate scientific research ability. Thirdly, the university-affiliated think tanks should establish rules and regulations suitable for the application and transformation of the research achievements, encourage faculty to provide research achievements for the think tanks to adopt; Fourthly, the university-affiliated think tanks should change the style of the theoretical research, and attach importance to providing targeted, empirical and feasible suggestions for practical problems.

\subsection{University-affiliated think tanks attach importance to all-media publicity and brand building}

The universities have always been regarded as "ivory towers" and not to seek fame and fortune, which is a good style of study for academic research. However, for the university-affiliated think tanks, in order to better serve the local economic construction and development, they must actively participate in the social practice, solve the actual 
problems in the development of local economy. Therefore, the university-affiliated think tanks should promote themselves, cultivate brands and gain the trust of government departments and society, then open up the channel through which the university-affiliated think tanks can serve the local economic development better. Therefore, the university-affiliated think tanks should use all-media to promote their own consulting products and well-known experts to establish a good brand image in the public.

\section{Acknowledgement}

This paper was financially supported by the project of Science and Technology Plan of Xiangxi Autonomous Prefecture, "The Research on the Mechanism of University -affiliated think tanks participating in Local Science and Technology Innovation Decision-making consultation" (No.2018SF5015).

\section{References}

1. Wu Guosheng. What is science [M]. Guangzhou: Guangdong People's Press, 115-129(2016).

2. Xu Qingsen. Three relationships should be handled well in the construction of the university-affiliated think tanks $[\mathrm{J}]$. Theory and practice of think tank, 8-9 (2017).

3. Li gang. " University and think tank ":" South Great think-tank "general sequence idea of the broker: think tank and the rise of the new policy elite [M]. Nanjing: Nanjing University Press, 1-9 (2016).

4. Zhouyang, Lu Shengjun. Some thoughts on the construction of National defense science and Technology think tank under the new situation [J]. Theory and practice of think tank, 61-67(2016).

5. Lu Shengjun, Wang Yang, jamming and so on. Preliminary thoughts on the construction of new national defense decision-making consulting system in China [J]. Theory and practice of think tank, 4247(2016). 